\title{
DIE PRAKTYK VAN KERKVISITASIE
}

\section{Inleiding}

Die visitasie moet uiteraard verstaan word in die volle sin van die Gereformeerde kerkregering. Dit gaan beslis nie oor 'n vertolking van een artikel in 'n Kerkorde soos van 'n artikel in 'n wet of sekulêre sisteem nie. Agter die visitasie lê die dinamiese beginsel dat Christus sy kerk regeer en dat Hy die ekklesia geroep en ook gekroon het met gawes, bevoegdhede en verpligtinge, sodat sy Woord en Gees die gemeente in goeie orde en welstand kan hou. Middellik deur die gemeente roep Christus voorgangers om te regeer - en met die oog hierop kom hulle ook in kerkraad saam.

Die visitasie moet dus gesien word in harmonie met die totaliteit van beginsels, bv. een kerk mag nie oor 'n ander kerk, een dienaar nie oor 'n ander dienaar, visitatore (as predikante) nie oor ouderlinge enige heerskappy voer nie; die klassis is 'n vergadering van naburige kerkrade (en dus nie 'n permanente struktuur met eie personeel en kontinuiteit in of d.m.v. visitatore nie); die kerkraad is die primêre en enigste permanente vergaderingstruktuur (al handel hy ook met „adviese", „oordele" of „besluite" wat in kerkverband saam met ander kerkrade ter klassis of sinodes geneem is), ens. Kortom, sodra "die klassis" d.m.v. die visitasie los van, langs, teenoor of oor die kerkraad begin opereer, het 'n ernstige kortsluiting ontstaan wat die wese van die Gereformeerde kerkregering aantas. Die kerkverband staan in gereformeerde kerkreg nie teenoor die selfstandigheid van die plaaslike kerk nie, maar vloei juis daaruit voort. Die ekklesia is immers volledig en kompleet kerk.

\section{Kort geskiedenis van die visitasie}

Bouwman ${ }^{1}$ wys dat die idee van visitasie as 'n besoek so oud is soos die kerk self (Hand. $9: 32 ; 15: 41 ; 16: 4 ; 18: 23 ; 1$ Kor. $4: 19$; $16: 5-8$ ). Die idee dat visitatore eintlik die biskop verteenwoordig, kom reeds op die Sinode van Laodicea (363) voor en speel 'n rol in die ontwikkeling van die pousdom. Karel die Grote gebruik die visitasie deur biskoppe in sy verligte opvoedingsbeleid om belange van kerk, onderwys en godsdiens te dien. So bedoel die Roomse idee van visitasie deur die biskop dan ook dat die Pous hom kan laat verteenwoordig deur sy gesante. M.a.w. die visitasie, die visitator, vergestalt 'n besoek van die Pous d.m.v. 'n afgesant.

Luther het aan die visitasie aandag gegee. Vanweë die verval van kerke en skole en die swak toestand op die gebied van volksonderwys ontwikkel hy gedurende die tydperk 1525-1528 die „Kurfurstliche Visitation". Hier ontvang die landsheer die patronaat posisie van die Pous in die Roomse visitasie. In Skotland word reeds met die eerste Kerkorde 1560 ' $n$,instituut der superintendenten" ingerig. Dit was 'n kollege van omtrent 12 predikante of visitatore wat die opdrag gehad het om gemeentes te organiseer, nuwe gemeentes te stig, toesig te hou oor die lewe en die werk van die predikante en dan van daardie werk verslag te doen op die Sinode. Dit was 'n tydelike instelling, maar hierdie superintendenteskap 
het in die Skotse kerk 'n permanente instelling geword.

A Lasco is in 1546 ook deur die owerheid as 'n superintendent benoem en hy het dit ook beoefen met die oog op die bewaring van die goeie orde en die tug in die kerk.

Wanneer $u$ hierdie agtergrond in die oog hou, sal $u$ verstaan dat die Gereformeerdes baie bang was dat visitasie die weg vir hiërargie sou open. Hulle was huiwerig vir visitasie omdat die beginsel van hiërargie sou beteken dat menslike instellings en gesag die plek neem van Christus en sy Woord. Die Sinode van Emden het 1571 in sy heel eerste artikel enige vorm van hiërargie afgewys en die beginsel is vandag in ons Art. 84 vasgelê.

Wanneer Zeeland die Sinode van Middelburg 1581 vra om ,jaarlikse besoekinge" dan wys die Sinode dit af as onnodig en gevaarlik of bedenklik (sorglik).

Ons moet die baie moeilike situasie van die kerk in ag neem. Eerstens het baie voorgangers 'n Roomse agtergrond gehad en was aan baie verkeerde dinge gewoond. Tweedens het die RenaissanceHumanisme die Libertinisme opgeroep en ter wille van die kerk is geroep om die kerkvisitasie. Dit het daartoe gelei dat die Sinode van Den Haag in 1586, in Art. 40 die saak van kerkvisitasie gereël het.

(1) Die visitatore moes gaan preke aanhoor; hulle moes gaan let op die leer wat die predikante voorstaan en veral of die predikante ywerig is om die Skrif te bestudeer en hoedanig hulle liturgies optree wanneer hulle doop en nagmaal bedien ens.

(2) Hulle moes versigtig let op die ouderlinge en diakens, of hulle besig is om die kerk op te bou, of hulle die Christelike tug handhaaf en of hulle vergaderings hou.

(3) Hulle moes let op twis en onenighede en onordelikhede wat tot nadeel van die kerk is en dit moes hulle "met spoed verbeter".

(4) Waar foute gevind word moet hulle eers die besondere persone vermaan, en dis ook belangrik vir die gang van die saak (Matt. 18). As dit nie help nie, moet hulle dit in die kerkraad stel en eers as dit misluk, moes die saak by 'n klassikale vergadering aangedien word.

Dit is nogal opmerklik dat die woord inspeksie dikwels gebruik word by hierdie visitasie maar tegelyk word die idee van ,inspectore" namens 'n klassis, of die idee van superintendente op grond van persoonlike waardigheid radikaal afgewys. Dit gaan dus om 'n ,inspeksie" in en vir die kerk self met die oog op die gesitueerdheid van die kerk t.o.v. die Koning.

Die Sinode van Dordt het vanweë die ontsettende beroeringe wat de Remonstrante in die kerk gebring het Art. 44 geformuleer, min of meer soos ons dit vandag het. Destyds het die visitasie beoog om die leer en lewe, d.w.s. die situasie teenoor Skrif, Belydenis en orde (teenoor die libertynse remonstrantisme) te bewaak.

Opmerklik genoeg sê Bouwman dat 'n visitator moet 'n visitasiereglement net as ' $n$ handleiding beskou. Die hoofsaak was dat hy sy vrae en werk met erns en noukeurigheid moes doen. Hy sê visitasie mag nooit ,een inquisitoriaal ondersoek" word en ontaard tot „opdreunen van de vragen", en daarom moet dit met wysheid die 
heil van die gemeente steeds voor oë hou. Visitasie word dus nie gestruktureer ten dienste van 'n klassis nie, maar met die oog op die heil van die kerk. Die heil word bepaal deur die relasie ChristusKerk en nie deur 'n relasie klassis-gemeente nie.

\section{Prinsipiële basis van die visitasie}

3.1. Bouwman wys op die besoeke van die apostels waar Paulus by name aan Bárnabas in Hand. 15 : 36 sê dat hulle moet gaan om sekere dinge te gaan vasstel by die gemeente. Dit is 'n belangrike beginsel.

Kerkvisitasie kom op uit 'n band wat die apostel voel met die kerke wat tot stand gekom het deur sy en Bárnabas se bearbeiding. Dit geskied hier nie soos met sy eerste sendingreis in opdrag van Antiochië nie. Dit geskied nie eers uit 'n opdrag van die samekoms van Hand. 15 nie. En nog belangriker, dit geskied hoegenaamd nie met die oog daarop om iets omtrent die kerk te gaan vasstel en om dit te gaan rapporteer by ' $n$ tweede of derde instansie of enige kollegium nie. Hierdie besoeke vind plaas kragtens 'n roeping tot diens. Dit vind plaas kragtens die relasie waarin die apostel tot die Here Christus en dientengevolge t.o.v. die kerke staan. Dit geskied met geen ander doel as uit bewoënheid van die dienaar oor die welsyn van die kerke nie, d.w.s. uitsluitend met die oog op die relasie waarin die kerke tot Christus (die Woord van God) staan.

Opsomming: Kerkvisitasie vind plaas met die oog op die verantwoording van die dienaar (visitator) en kerk aan Christus - en nie met die oog op verantwoording aan 'n newestaande instansie soos die Biskop (by Rome) of landheer (by Luther); of 'n vergadering of kollegium (by kollegialisme) nie.

3.2. Bouwman fundeer die besoek op „eenheid van die kerk en kerkverband" (II, p. 174). Dit gaan hier om die behoud van die geloofsband en die handhawing van ,de ordinantiën van Koning Jezus". Elke kerk het vir sy instandhouding, uitbreiding en suiwerheld van leer die genabuurde kerke nodig. Ons kan nie van Bouwman verskil nie. Tog voel ek by nadenke dat hierdie formulering mank gaan aan 'n tipiese gebrek by baie van ons kerkregtelike besinninge. Ons neig dikwels om die formele, die institusionele, voorop te plaas. Die eenheid waaruit visitasie kragtens "kerkverband" opkom, is primêr nie die institusionele organisasie nie, maar korrespondensie as ooreenstemming, ooreenstemming as gemeenskap (koinonia), eenwees-in-die-Here en deel-hê-aan-dieselfde Here. Daarom moet visitasie primêr toegespits wees op hierdie essensiële, d.w.s. die een-wees-indie-Here. Dit gaan primêr om die leereenheid en leersuiwerheid en daarom ook 'n lewenseenheid wat daarop neerkom dat die Woord van die Here gehandhaaf moet word.

Kortom, dit gaan om die heerskappy van Christus in sy Kerk en nie om die soort verwesenliking van 'n eenvormige formalistiese kerkverband wat rus op die besluite van vergaderings, ens. nie. Die visitator ontleen sy enigste mandaat tot visitasie aan Christus en nie aan 'n Kerkorde-artikel, of erger nog, 'n klassisbenoeming nie. 
3.3. M.i. is dit van kardinale belang om te vra: Watter hulp wil die kerkvisitasie bied? Ek wil eerstens verwys na die woord „dienaar" in Art. $44 \mathrm{~K} .0$. wat gekwalifiseer word met „oudste, geskikste en mees ervare". Die adjektiewe sou bloot horisontaal verstaan kon word maar die oorspronklike bedoel seker hier om juis kragtens die kerkverband en die eenheid in die Here, verskillende gemeentes te laat profiteer van die gawes $(\chi \alpha \rho \iota \sigma \mu \alpha \tau \alpha)$ wat God aan sekere geroepe dienaars gegee het (Rom. 12:6). Die visitatore kom dus kragtens die kerkverband in hulle amp as 'n bedienaar van die Woord en ontvang dié staanplek in die kerk wat hy besoek. Ons moet visitasie fundeer in die diens van die Woord waartoe die Here hierdie broeders geroep het en ons moet wegkom van 'n formele fundering van visitasie in ' $n$ blote opdrag van 'n vergadering. Ek gaan nie nou op sekondêre formele kwessies in nie. Ek beklemtoon die kardinale belangrikheid om die visitator in die praktyk as dienaar te bly sien, in sy diens van die goddelike Woord waartoe die Here hom geroep het. Uit sy roeping, sy ervaring en sy ondervinding, kortom, as 'n gawe van God, moet hy in genabuurde kerke gaan visitasie doen. Die klassis vervul slegs 'n middellike rol om die visitator en kerk byeen te bring.

3.4. Sodoende beteken visitator doodeenvoudig „besoeker” en kerkvisitasie 'n ",besoek" wat een kerk van dienaars van ander kerke ontvang, kragtens kerkverband met die oog daarop dat die kerk van Christus van hulle diens aldaar sal profiteer tot opbou van die liggaam (of volk) van die Here (of Koning) vgl. Ef. $4: 11-16$.

3.5. Die kerke in die klassis se taak is om hierdie dienaars aan te wys. Art. 49 K.O. gee die beginsel en die voorskrif van hoe daar moet opgetree word wanneer mense namens 'n vergadering moet handel. Hierdie voorskriftelikheid ontbreek by Art. 44 K.O. Die klassis se opdrag kom net neer op: „Gaan besoek daardie kerk in die diens waarin julle as dienaars staan; doen die werk waartoe die Here julle geroep het". Hierdie vertolking word met woorde uit Art. 44 K.O. bewys: ,gereelde kerkvisitasie te hou" d.w.s. gereelde besoeke te gaan aflê; ,vas te stel of ..." d.w.s. jouself daar oop en bloot in die kerk op hoogte te stel met die diens wat jy daar moet verrig; „betyds broederlik kan vermaan”, d.w.s. hierdie vermaan rus op gesag wat die visitator besit kragtens sy roeping van God in die diens waarin hy staan; "met raad en daad alles te kan help reël wat bevorderlik is vir die vrede, die opbou en belange van die kerk", d.w.s. daar ter plaatse handel, maar in volle harmonie met die plaaslike opsieners.

3.6. Wanneer daar verskil intree tussen die visitatore en die kerkraad of wanneer die visitatore oordeel dat 'n kerkraad in sy handelinge wat hy daar in hulle teenwoordigheid uitvoer, die reg krenk, neem die visitatore die saak na die klassis. Hulle kan in 'n aparte appèl of in die vorm van 'n visitasierapport doen - die vorm is immers diensbaar aan die saak. Die heerskappy van Christus en die verwesenliking van sy wil is altyd meer as die papiertjie wat opgestuur word. 


\section{Ontwikkeling van art. 44 K.O. sedert die Sinode van Dordt $1618 / 19$}

4.1. In teorie staan ons met Art. 44 nog eintlik maar by $1618 / 19$.

4.2. Ek wil verwys na Art. 52 van die nuwe Nederlandse K.O. en na Nauta se verklaring hiervan. ${ }^{2}$ Die artikel mak voorsiening vir 'n ouderling-visitator naas 'n predikant; laat die ondersoek na onderwys heeltemal weg; en verplig die visitatore om rapport aan die Klassis te doen.

\subsection{Christian Reformed Church Art. 42 van die V.S.A.s}

Globaal lyk die redusering van art. 44 baie soos dié van Nederland, maar daar is ook verskil. Hulle bepaal uitdruklik dat die kerke enige tyd visitatore kan inroep. Hulle beperk visitasie by „two of the more experienced and competent ministers".

\subsection{Tendense in hierdie ontwikkeling}

4.4.1. Hoewel die Nederlandse taaleie in ag geneem word, is dit opmerklik dat Nauta praat van die "instituut der kerkvisitatie". Hy sê die visitasie geskied „,vanwege de classis" en hy juig juis toe dat die min of meer permanente aanwysing van visitatore afgesny word deur jaarlikse aanwysing. By Nauta weeg die funksie en optrede van die klassis swaar. Ek het vrede met jaarlikse aanwysing dit is formeel. Ek het beswaar wanneer die klassis in die visitator fungeer en visitasie ' $n$ min of meer institusionele karakter aanneem: 'n gebeure tussen 'n kerkraad en klassis wat selfs nie eers in die kerkraadsnotule nie, maar in „visitatore-verslae" genotuleer word!!

4.4.2. Die neiging tot verselfstandiging van die visitasie blyk wanneer Nauta 'n Huishoudelike Reglement nodig ag. Die visitatore moet toesig uitoefen oor mede-ampsdraers en die visitatore dra „een eigen verantwoordelijkheid" waarteen „een ambtsdrager of een kerkraad zonder meer niet kan of mag worden aangetast". Hy fundeer sy uitleg daarop „omdat visitatoren alleen in opdracht en met volmacht van de classis kunnen handelen". Hy fundeer visitasie in die klassis in plaas van Christus, en kom daarom volledig met kollegialisme ooreen.

4.4.3. Monsma is baie positief dat die visitatore se ,toesig" nooit kan wees dié van 'n ,authoritative body over inferior bodies" nie - wat by Nauta wel deurgeskemer het. Nietemin hou ek nie van Monsma se fondament vir sy stelling nie: „The various churches comprising a classis, being all equal in authority, supervise each other. Consequently the visitors are also appointed by these churches themselves as their representatives for this work". Sy uitleg is suiwer maar sy fundering dra ook eintlik die gedagte van ecclesiastiese delegasie, eerder as werklike, wesenlike kerkregering deur die Woord en Gees. Dit kom tog neer op 'n vorm van magsverlening waardeur bediening en die hele begrip van 'n dienskneg wat minder word en Christus wat meer word, verdwyn. Die klassis word 'n soort middelaar wat in hierdie bediening tussenin skuif. Ons bely nie in Heid. 
Kat. Sondag 21 dat klassisse of vergaderinge die kerk bou nie, maar dat Christus met sy Woord en Gees sy gemeente vergader, beskerm en onderhou. Dit is die enigste „authority", waartussen geen pous en geen vergadering kan indring nie.

4.4.4. 'n Primêre vraag vir die praktyk van kerkvisitasie is: Wat is Gereformeerde kerkregering? Is dit primêr aan presbiters of aan die vergaderings van dienaars opgedra?

4.4.5. Wanneer Monsma ook wil redeneer dat die visitasie kan geskied in die kapasiteit van die predikant as 'n regeerouderling en nie soseer in sy kapasiteit as 'n leerouderling nie (p. 773), klink dit formalisties. Die Sinode van die CRC van 1922 het vraelyste vir visitasie voorgeskryf. Die Sinode van 1936 het hierdie „meganisasie” van die visitasie weer afgewys en beklemtoon dat visitasie moet plaasvind "through discussion".

4.4.6. Monsma beklemtoon m.i. meer as Nauta, dat die plek vir visitasie die kerk en die kerkraad is. Daardeur wys hy op sake wat in die praktyk van belang is: jaarlikse besoeke; die noodsaaklikheid dat daar soveel besoeke gebring moet word as wat die kerkraad vra, m.a.w. die visitasie gaan primêr uit van die kerkraad en sy behoeftes en nie van 'n klassis nie; hy benadruk dat die visitatore net kan advies gee, terwyl by Nauta die gedagte na vore kom dat visitatore tot bevindinge en tot bindinge d.m.v. hulle klassikale gesag kan kom; Monsma benadruk: "The true welfare of the churches demands a certain measure of secrecy" (d.w.s. geen rapporte nie); hy benadruk dat die visitasie genotuleer moet word in die notuleboek van die kerkraad en by voorkeur deur die skriba eerder as deur een van die visitatore.

Monsma wys op die ekonomie en tydsbesteding in die verloop van visitasie. Die visitatore moet hulle eerstens toespits op „matters which requires special attention" en tweedens op „questions which the consistory may desire to represent". Dit vereis natuurlik nie net 'n behoorlike voorbereiding van die visitatore nie, maar ook van die kerkraad. Hy ontmoedig dus 'n ,,informal discussion".

Die reël van 1922 het voorsiening gemaak vir afsonderlike onderhoude met verskillende ampsdraers. Visitasie moes liefs in die hele vergadering gehou word "to broach the matter in the presence of the party or parties concerned". Die C.R.C. vereis sedert 1942 dat ,all questions are asked in the presence of all", sodat "agteraf" informasie kry of aanbevelings deurstuur, uit is.

Die C.R.C. beklemtoon dat visitasie nie die plek is vir onderlinge klagtes nie. Daar moet slegs op klagtes ingegaan word as dit geword het ,a condition which requires correction".

Inspeksie wat toespits op finansies, salarisse, geboue en administrasiekwessies soos in die Nedl. Herv. Kerk gebeur het, veroorsaak dat ,the spiritual emphasis was lost. The real task of the visitors was largely or wholly neglected". Monsma ag dit nie nodig dat visitatore hulle bevindinge juis persoonlik onder hulle handtekening in die notuleboek teken nie. Die skriba se aantekeninge is volgens hom genoeg. Hoewel Monsma en Nauta verwys na 'n verslag van die visitasie aan die klassis, sê hulle eintlik weinig daarvan. Monsma meen dit is net vir liassering en toekomstige referensie. Mens sou 
egter kon vra: Waarom die duplikasie, wanneer die bevindinge in die notule van die kerkraad refereerbaar bly?

\section{Voorbeelde van ons huidige praktyk}

5.1. Reglemente vir visitasie is dikwels in omloop.

5.2.1. Institusionalisering en verselfstandiging van formele dinge, sodat dit eintlik tot die wesenlike verhef word. Die blote praktiese onderskeiding tussen gewone en buitengewone visitasie het al feitlik twee visitasies geword!

5.2.1. Die verwarring tussen Art. 44 en 49 K.O. dra die beginsel van 49 oor na art. 44 en van visitatore word deputate gemaak.

5.2.2. Met ' $n$ beroep op klassis en visitasie ontvang visitatore ' $n$ oop mandaat. Die klassis het 'n visitator benoem, daarom kan hy in naam van die klassis enige iets wat tot visitasie behoort op gesag en in opdrag van die klassis behandel. So gebeur dit dat visitasie buite die kerkraad se notule om geskied, dat 'n verslag daarna aan die klassis en slegs 'n afskrif aan die kerkraad gestuur word; en die aanbevelings van die visitatore met klassisgesag gelaai word en dan op die arme kerkraad gebombardeer word. vloei.

5.2.3. Verkragting van beginsels moet uit derglike praktyke

5.2.3.1. Dit verkrag die selfstandigheid van die roeping van God vir die betrokke dienaar, kerkraad en die bepaalde kerk, warop ons reeds vroeër gewys het.4

5.2.3.2. Die voorskriftelikheid t.o.v. non-essensiële dinge: soos die aandiening van stokperdjies van visitatore t.o.v. administrasie, aktivering, liturgie ens., klassikale-traktementskale, voorgeskrewe prosedures, ens.

5.2.3.3. Die gevaar dat die beginsel van Art. 84 K.0. en Art. 1 van die Sinode van Emden 1571 verkrag word, is nie meer denkbeeldig wanneer visitatore diagnoseer, die klassis adviseer en dan op die kerkraad se tafel gelê word nie.

5.2.3.4. Art. 30 K.O. word verkrag wanneer visitatore sake voor 'n klassis rapporteer wat in die kerkraad afgehandel is of kon word.

5.2.3.5. Skrifbeginsels in Matt. 18 en 1 Kor. 13, ens. kom dikwels in gedrang. Visitatore hoor dikwels allerlei griewe, klagte en agterklap. Wanneer dit buite 'n kerkraad om in 'n verslag voor 'n klassis genoem word, is 'n ordelike behandeling onmoontlik.

5.3. Enkele oorsake vir verval van die visitasie:

5.3.1. Schizofrenie kan tussen teorie en praktyk ontwikkel eerstens omdat die pragmatiese vir ons baie swaar weeg en tweedens wanneer die formalistiese en die formele die visitasie beheer.

5.3.2. Ons Westerse voorliefde vir institusionalisme en ons maklike na-apery van wat in die sekulêre wêreld gebeur, neig altyd weer om die klassis in die visitatore te plaas, i.p.v. dat visitatore en kerk saam in-die-Here ontmoet.

5.3.3. Die begrip van magsdelegasie kweek die opvatting dat visitatore namens, vir en op gesag van 'n klassis optree. Prof. F. L. 
Rutgers $^{5}$ sê die Kerkorde ken geen ander kolleges as dié van Art. 29 K.O. nie. Die visitasie is dus nie iets eiesoortigs soos 'n besoek van provinsiale inspekteurs by 'n munisipaliteit nie. Niemand het die reg om ' $n$ besluit te neem buite 'n kerkraad om t.o.v. 'n gemeente nie. Anders sou die instansie 'n mag van regering, 'n regspraak of waardigheid of voorrang verteenwoordig wat biskoplik is. Voetius het gesê: Geen kerk kan sy mag aan 'n persoon oordra nie en die groot beginsel is dat die kerk self in vergadering alle sake moet reël (aangehaal by Rutgers). Die praktyk van visitasie-rapporte buite die kerk om, gaan nie op nie.

5.3.4. Luther het gesê die behoefte om 'n pous te wees, sit tog maar in elkeen van ons harte. Die sonde kan ook op visitasie na vore kom.

\section{Samevatting vir die ideale visitasie}

6.1. Die visitasie moet waarlik die karakter van 'n broederlike besoek van bekwame dienaars van die Here aan 'n kerk van die Here ten dienste van die Woord en die Gees van die Here openbaar.

6.2. Daar moet van die feit uitgegaan word dat die dienaars van die kerk (ouderlinge, diakens en dominees) net soos die visitatore geroep is en dat hulle daarom saam moet worstel oor die kerk van die Here.

6.3. Visitatore moet bewoë wees om die kerk van die Here te gaan dien met die gawes wat hulle eie is. Wie gaan omdat die klassis hom aangewys het, dink horisontaal en kan gerus tuisbly. Wie hom nie primêr aan die Here verantwoord nie, is gewoonlik haastig om gou by die huis te kom en sal dan "later" advies of verslag stuur. Die ideale visitator „help reël” onmiddellik, aldaar.

6.4. Die visitator moet hom vir sy vermanings op Christus kan beroep en nie op die klassis, die tradisie of die "demokratiese" giere nie. Hy moet derhalwe die middelmatige dinge vermy.

6.5. Die metode wat ons toepas moet bepaal word deur omstandighede en nie deur voorskriftelike visitasie nie. Dit is seker die beste as 'n kerkraad besin en dan ' $n$ agenda aan die visitatore gee vir die visitasie.

6.6. Bevindinge en adviese wat gegee of gevra word, moet genotuleer word in die notule van die kerkraad. Die beginsel van Art. 30 moet nagekom word sodat sake afgehandel word waar dit tuishoort. Wat afgehandel is, durf nie weer op 'n klassistafel in 'n rapport vermeld word nie.

6.7. Die verslag aan die klassis moet bloot formeel wees, dat die visitasie gehou en gewaardeer is, ens.

6.8. Konkrete materiële verslag moet aan die klassis gedoen word wanneer die saak volgens Art. 31 K.O. vir 'n oordeel voorgelê word. Enkele sake mag goedskiks onder art. $41^{\circ} \mathrm{K} .0$. as 'n beskrywingspunt gestel word. 
6.9. As die kerkraad nie met die advies van visitatore saamgestem het nie en die visitatore het nie genoeg gronde om kragtens Art. 31 K.O. in appèl te gaan nie, dan het die klassis inderdaad met daardie saak niks te doen nie.

(Gelewer voor G.T.V. Johannesburg, 20-5-1974)

B. Spoelstra.

1 H. Bouwman: Geref. Kerkrecht, Kampen 1934, dl. II, p. 157 en dl. I, p. 156.

2 D. Nauta: Verklaring van de Kerkorde van de Gereformeerde Kerken van Nederland.

3 M. Monsma: The New Revised Church Order Commentary, Grand Rapids, 1967.

4 Vgl.: In die Skriflig, Nr. 28, p. 20.

5 Kerkelijke Adviezen, Kampen 1921, I, p. 313. 